\title{
Monitoring of Visuomotor Coordination in Healthy Subjects and Patients with Stroke and Parkinson's Disease: An Application Study Using the PABLOR-Device
}

Rüdiger J. Seitz ${ }^{{ }^{*}}$, Alexander Kammerzell' ${ }^{1}$, Melina Samartzi ${ }^{1}$, Sebastian Jander ${ }^{1}$, Lars Wojtecki ${ }^{1}$, Paul F.M.J. Verschure ${ }^{2}$ and David Ram $^{3}$

${ }^{1}$ Department of Neurology, University Hospital Düsseldorf, Moorenstrasse, Germany

${ }^{2}$ SPECS Lab, Universitat Pompeu Fabra, Roc Boronat, Barcelona, Spain

${ }^{3}$ Tyromotion $\mathrm{GmbH}$, Bahnhofgürtel 59, Graz, Austria

\begin{abstract}
Background: Visuomotor performance can be improved by repetitive training on consecutive days. The aim of this study was to assess the training effect of visuomotor tracking in healthy subjects and hemiparetic patients with stroke and in moderately impaired patients with Parkinson's disease.
\end{abstract}

Methods: 39 healthy right-handed subjects, 15 patients after acute cerebral artery stroke, and 15 patients with mid-stage Parkinson's disease were trained with the commercially available, multifunctional PABLOR-device. This handhold device is equipped with force and acceleration sensors and connected to a personal computer for on-line data display and data storage. On three consecutive days the subjects were trained to navigate a target through obstacles in a virtual reality environment. Performance was assessed by modulation of force production and rotation of the hand in a visuomotor tracking paradigm using the PABLOR-device.

Results: The main findings were that training of the right dominant hand improved visuomotor coordination of hand rotation movements in both hands in the healthy subjects $(p=0.0015)$. Training of the right affected hand improved visuomotor coordination of hand rotation movements in either patient group $(p=0.026)$. In contrast, training improved the visuomotor coordination of force tracking of the dominant hand only in the healthy subjects $(p<0.01)$.

Conclusions: The visuomotor training scenario was effective to improve visually guided hand coordination within three days in the healthy controls and both patient groups. The improvement of hand rotation generalized to the nontrained hand in healthy subjects.

Keywords: Stroke; Parkinson's disease; Healthy subjects; Training; Hand movements; Visuomotor coordination

\section{Background}

Human hand function is determined by a number of aiming movements with different degrees of freedom involving the shoulder, elbow, wrist and fingers. Most important are elevations of the hand and arm as produced by movements at the shoulder joint, grip force exertion with the hand, pinch grip of index finger and thumb, fractionated finger movements for object exploration, as well as rotating movements of the hand resulting in a supination or pronation of the wrist. These movements can be affected differentially by diseases of the central and peripheral nervous system.

Weakness of limb movements is usually assessed by the semiquantitative scale of the medical research council (MRC-scale [1]). Computations of the MRC values of proximal and distal muscles both in the arm and leg provide a comprehensive score value for the entire motor system [2]. However, for assessing the functional impairment of the hand, manual tests have been developed such as the nine hole peg test [3], the Tayler-Jebsen test [4], and the Fugl-Meyer test [5] that investigate the use of the hand in different conditions providing semiquantative data on the quality of performance and quantitative data concerning the time needed to complete the task items. In patients with Parkinson's disease slowing of movements due to bradykinesia, rigor and tremor are assessed semiquantitatively predominantly with the unified Parkinson disease ranking scale (MDS-UPDRS [6]). For longitudinal studies in the clinical field as well as in neurorehabilitation, however, quantitative measures of arm and hand movements are mandatory to monitor the effect of therapeutic interventions.

For therapeutic interventions the acquisition of visuomotor skills appears as a potential model. In skill acquisition different phases including sequence learning of movements, sensorimotor association and consolidation of performance have been described [7-9]. An important aspect of motor learning is that expertise requires many repetitions of task performance on consecutive days [10]. Notably, there is evidence that sleep promotes the consolidation of such memory [11]. As was shown in neurophysiological and neuroimaging studies, prefrontal, premotor and parietal cortical areas as well as subcortical structures such as the basal ganglia and cerebellum participate in these processes in a task-specific manner [12-14]. However, it is unclear if such findings in healthy volunteers translate into the processes of brain plasticity in brain diseases. For example, in stroke the location of the brain lesion may interfere with the motor circuitry and, thus, the ability to acquire new skills [15]. Interestingly, in acute stroke the motor function of the ipsilateral non-affected hand is also impaired [16]. Likewise, the abnormal Dopa-transmission in the nigrostriatal pathway in patients with Parkinson's disease was reported to impair the acquisition of new motor skills [17]. Accordingly, acute stroke and chronic Parkinson's disease are characterized by well defined but different changes interfering with motor performance in man.

*Corresponding author: Rüdiger J. Seitz, Department of Neurology, University Hospital Düsseldorf, Moorenstrasse 5, 40225 Düsseldorf, Germany, Tel: +49211-922-4600; E-mail: seitz@neurologie.uni-duesseldorf.de

Received June 24, 2014; Accepted July 25, 2014; Published August 20, 2014

Citation: Seitz RJ, Kammerzell A, Samartzi M, Jander S, Wojtecki L, et al. (2014) Monitoring of Visuomotor Coordination in Healthy Subjects and Patients with Stroke and Parkinson's Disease: An Application Study Using the PABLOR-Device. Int J Neurorehabilitation 1: 113. doi:10.4172/2376-0281.1000113

Copyright: ( 2014 Seitz RJ, et al. This is an open-access article distributed under the terms of the Creative Commons Attribution License, which permits unrestricted use, distribution, and reproduction in any medium, provided the original author and source are credited. 
Citation: Seitz RJ, Kammerzell A, Samartzi M, Jander S, Wojtecki L, et al. (2014) Monitoring of Visuomotor Coordination in Healthy Subjects and Patients with Stroke and Parkinson's Disease: An Application Study Using the PABLOR-Device. Int J Neurorehabilitation 1: 113. doi:10.4172/2376-0281.1000113

Page 2 of 8

In a proof of principle study, we sought to monitor the effect of visuomotor training using the commercially available multi-purpose $\mathrm{PABLO}^{\mathrm{R}}$-device. This multifunctional, handhold device contains pressure and acceleration sensors which allow measuring vertical, horizontal and rotating limb movements and grip force exertion with the hand and with the index finger and thumb. It has the option to assess definite motor functions in a user-independent quantitative manner. In addition, gaming scenarios can be used for the training of visuomotor tracking skills. In this study, we aimed at testing the following hypotheses:

1. Training over consecutive days improves grip force modulation and rotation of the hand and generalizes to the contralateral, non-trained hand in healthy subjects.

2. Training of grip force modulation and rotation of the hand over consecutive days improves the affected hand in patients suffering from brain diseases e.g. after stroke and in Parkinson's disease.

\section{Methods}

\section{Subjects}

39 healthy right-handed subjects were recruited for the study. Subgroup A of 19 subjects included 9 men and was aged $39 \pm 15$ (SD) years and was trained with their right hand (see below). Subgroup B of 20 subjects included 11 men and was aged $25 \pm 2(\mathrm{SD})$ years and was trained with their left hand (see below). Handedness as assessed with the Edinburgh handedness questionnaire [18] showed a right-handed score of $96 \pm 4$ percent.

In addition, 15 consecutive patients aged $61 \pm 12(\mathrm{SD})$ years who were treated at our stroke unit because of an acute mild hemiparetic brain infarction mainly affecting the hand motor function ( $5 \pm 3$ days after stroke) were included as one patient group (Table 1). There were 4 women and 2 left-handed patients. As verified by cranial magnetic resonance imaging 13 patients had an infarct in the middle cerebral artery territory, one in the basal ganglia and one in the pons. At the time of investigation they were moderately affected with a median NIH Stroke scale [19] of 3. Four patients had been treated with thrombolysis. A second group comprised 15 consecutive right-handed male patients aged $70 \pm 6$ (SD) who suffered from Parkinson's disease for $7 \pm 4$ (SD) years and were treated in our clinic (Table 1). They were at the mid stage of the disease having a moderate disability corresponding to stage 3 in the scale of Hoehn and Yahr [20]. This involved a pronounced rigor affecting arm function on both sides of their body and postural instability when off dopaminergic medication. They were on treatment with L-DOPA, rasagilin and dopamine agonists such as peripidil, pramipexol etc. At the time of investigation the patients were in a stable "on"-state which allowed them to perform the task. In particular,

Table 1: Patient Demographics

\begin{tabular}{|c|c|c|c|c|}
\hline \multicolumn{5}{|c|}{ Stroke Patients } \\
\hline Age (ys) & Gender & Neurological Deficit & $\begin{array}{l}\text { Time since } \\
\text { stroke (d) }\end{array}$ & \\
\hline $61 \pm 12$ & $11 \mathrm{~m} / 4 \mathrm{f}$ & NIHSS 3 (1-9) & $5 \pm 3$ & \\
\hline \multicolumn{5}{|c|}{ Parkinson Patients } \\
\hline Age (ys) & Gender & $\begin{array}{l}\text { Neurological } \\
\text { Disability }\end{array}$ & $\begin{array}{l}\text { Disease duration } \\
\text { (ys) }\end{array}$ & $\begin{array}{l}\text { L-DOPA } \\
\text { dosage }\end{array}$ \\
\hline $70 \pm 6$ & $15 m$ & Stage 3 & $7 \pm 4$ & $388 \pm 96 \mathrm{mg}$ \\
\hline
\end{tabular}

NIHSS: Stroke Scale of the National Institute of Health [19] with median and range; stage 3 of Parkinson patients means a mild to moderate bilateral disability, postural instability but physical independence [20]. $d=$ days, $f=$ female, $m=$ male, ys $=$ years, mean $\pm S D$. none of the patients had a severe tremor which precluded performance of the task. The study was approved by the local Ethics Committee (\# 3221) and participation in the study followed informed consent of the patients.

\section{PABLO $^{\mathrm{R}}$-device}

The commercially available $\mathrm{PABLO}^{\mathrm{R}}$-device (Tyromotion, Graz, Austria) is a multi-purpose device designed for visuomotor training and for monitoring the learning effect during performance of the same task (Figure 1). The device has a handle like shape and is connected via USB to a $1.6 \mathrm{GHz}$ PC for operation. It comprises four sensors three of which are acceleration sensors working in the three dimensions of space. In addition, there is one force sensor. Data are recorded with a $50 \mathrm{~Hz}$ resolution as quantitative measures of force $(\mathrm{N})$ and angle (degree) and are stored as data files in ASCII format. Accordingly, the device allows quantitative measurements of an isometric grip force production with the hand, isometric force production with the pinch grip, and isotonic hand rotations leading to supination and pronation of the wrist. The measuring range for the isometric grip force production with the hand is $1000 \mathrm{~N}$, for the force production with the pinch grip it is $200 \mathrm{~N}$, and for hand rotations it is 180 degrees. In addition, it is designed to allow for assessing vertical and horizontal movements as for example during movements of the arm at the shoulder joint. Each of the movements can be calibrated to allow for a maximal range of action.

\section{Experimental procedure}

For the training sessions the healthy subjects were split into a subgroup A who was trained with their right hand and a subgroup $\mathrm{B}$ was trained with their left hand to assess the possible differences between the dominant and non-dominant hand. The stroke patients were trained with their affected hand, and the Parkinson patients with their right dominant hand only. Training consisted of one session on three consecutive days.

In the test sessions the subjects and patients were tested using the apparatus before and after the training sessions to assess their consequent movement performance in six measurements. The subjects and patients were requested to perform consecutive movements of their hand of 1 minute duration as described below. Half of the healthy subjects performed the measurements with their trained hand first, while the other half performed the measurements with their nontrained hand first. In the stroke patients training and measurements were performed with their affected hand, while Parkinson's patients measurements were performed with their trained right hand.

\section{Training session}

For training a number of different virtual reality gaming scenarios were available. In this project, the healthy subjects and patients viewed a virtual landscape on a computer screen displaying mountains, houses, trees and clouds (Figure 1). Also, there was a hot balloon which could be steered by the $\mathrm{PABLO}^{\mathrm{R}}$-device. The subjects' task was to act on the device such that the cursor moved up or down on screen. The calibration of the device before the trial made sure that the hot air balloon made a full vertical path in correspondence with the maximal range of action of the device. The motor task was either grip force of the hand, pinch grip of the index finger and thumb or hand rotation of the wrist (pro- and supination movements). During the training session the hot air balloon travelled from the left to the right passing by at houses, tries, mountains and clouds. The subjects' task was to steer the hot air balloon such that it would not bump into a mountain or cloud. When the subject was successful, movement speed of the balloon increased. The order of the 
Citation: Seitz RJ, Kammerzell A, Samartzi M, Jander S, Wojtecki L, et al. (2014) Monitoring of Visuomotor Coordination in Healthy Subjects and Patients with Stroke and Parkinson's Disease: An Application Study Using the PABLOR-Device. Int J Neurorehabilitation 1: 113. doi:10.4172/2376-0281.1000113

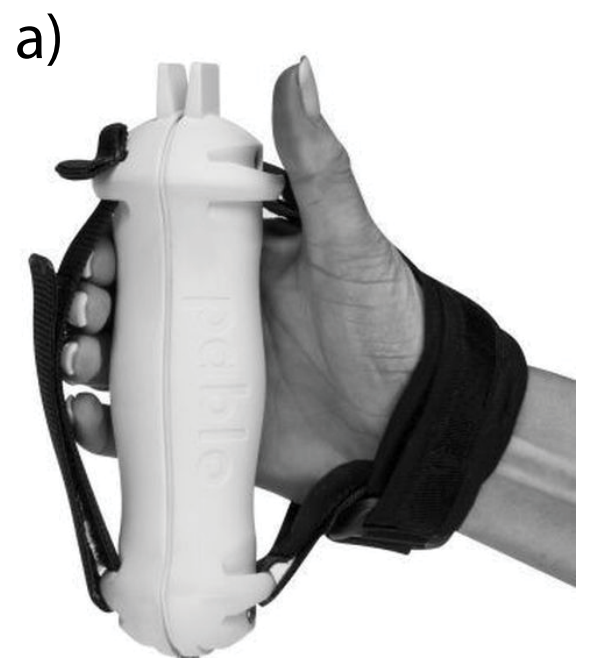

b)

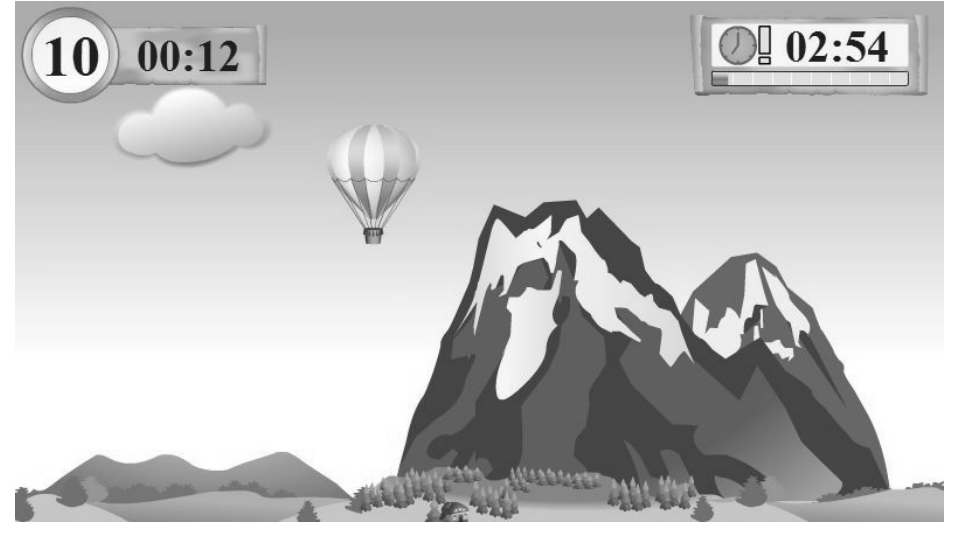

Figure 1: PABLOR-device with manual grip (a), gaming application (b).

different movement trials was pseudorandomly intermixed across the subjects. When the hot air balloon bumped into an obstacle, the travel speed of the balloon decreased. In each training session the subjects and patients performed 4 trials of 3 minutes duration for each of the three motor functions lasting for in total 36 minutes.

\section{Test session}

The subjects saw two coloured columns on the screen which were the motion of the target and the actual performance data generated with the $\mathrm{PABLO}^{\mathrm{R}}$-device, respectively (Figure 2 ). The subjects' task was to act on the device such that the column representing the performance data followed the height modulation of the target as closely as possible. The target data and the performance data had a $50 \mathrm{~Hz}$ resolution. The height modulation of the target was given by a sinusoidal increase and decrease of the column's size at a rate $0.5 \mathrm{~Hz}$ (Figure 2). The calibration of the device before testing guaranteed that the maximal height of the column representing the performance data was within the range of maximal possible movements of the target column. As in the training session, the motor task was either a grip force of the hand, a pinch grip of the index finger and thumb or a supination-pronation movement at the wrist (hand rotation). The test session lasted for one minute in which the subjects performed 30 movements of either of the three motor tasks. The test session was presented once before and after the training on each of the three days of training.

\section{Data analysis}

Data were analysed offline on a personal computer after transfer into Excel (Microsoft). In a first step, the performance data (actual tracking paths) were subtracted from the target data to provide an estimate of the deviation of the actual performance data from the sinusoidal target data. These data were force data in $\mathrm{N}$ or angles in degrees. In addition, the individual performance data were correlated with the target data using the Pearson correlation for the one-minute recording time of each test session. These correlation coefficients provided robust measures of the tracking accuracy of the subjects' hand movements.

Thereafter, the data of the actual tracking paths, deviation of the actual tracking path from the sinusoidal target data, and of the tracking accuracy were analysed by inferential statistics using the program STATVIEW $^{\mathrm{R}}$. First, it was investigated that the data were normally distributed using the Komolgorov-Smirnov test. Thereafter, the data were investigated using repeated measures ANOVA for the four experimental groups. Finally, group comparisons were calculated using the post-hoc t-test corrected for multiple comparisons. Only results surpassing a t-threshold of $<0.05$ corrected were accepted as significant.

\section{Results}

The healthy subjects and patients successfully performed the visuomotor tracking task in the gaming scenario and in the test sessions (Figure 2). ANOVA testing revealed that there was no change of the mean hand grip force and the mean pinch grip force as well as of the mean angle of hand rotation between the test sessions in either group (F-value 0.01; $\mathrm{p}=0.975$, DF 38 for healthy volunteers, DF 14 for either patient group). Likewise, the mean deviation of the actual performance data and the target data did not change across the test sessions.

In contrast, the tracking accuracy as indicated by the correlations of the actual tracking performance with the target data provided sensitive measures for the change of performance both in the healthy controls and stroke patients across the six consecutive test sessions. ANOVA testing showed that there was a significant group effect (F-value 14.437; $\mathrm{p}<0.0005$, DF 38 ) but no effect for the training sessions (F-value 4.311; $\mathrm{p}<0.07$, DF 38) for grip force modulation. There was no interaction of groups and training sessions. Post-hoc t-testing revealed that the force modulation in the trained hand of the healthy controls (groups A and $\mathrm{B}$ ) improved from the naive trial before the first training session to the final training session on the third day $(\mathrm{p}<0.01)$. But here was no change in the stroke or Parkinson patients. Notably there was no change for the pinch grip force $(\mathrm{p}>0.05)$.

An ANOVA of the tracking accuracy data showed that there was a significant group effect (F-value 12.825; $\mathrm{p}<0.02$, DF 14 ) as well as a significant effect for the training sessions (F-value 22.060; $<<0.0001$, DF 14) for the hand rotation task. There was a significant interaction between groups and training sessions (F-value 4.159, $\mathrm{p}<0.01, \mathrm{DF} 14$ ). Post-hoc t-testing revealed a significant improvement of hand rotation in the healthy controls (groups A and B) both for the trained right and the non-trained contralateral hand ( $\mathrm{p}=0.0015$; Figure 3$)$. Also, the 
Citation: Seitz RJ, Kammerzell A, Samartzi M, Jander S, Wojtecki L, et al. (2014) Monitoring of Visuomotor Coordination in Healthy Subjects and Patients with Stroke and Parkinson's Disease: An Application Study Using the PABLOR-Device. Int J Neurorehabilitation 1: 113. doi:10.4172/2376-0281.1000113

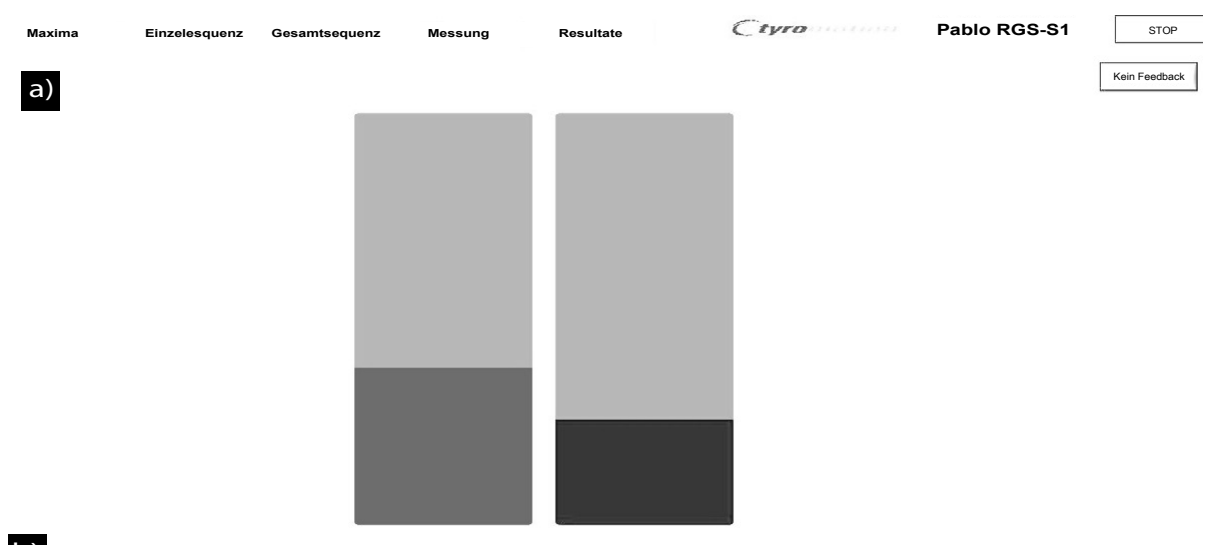

b)

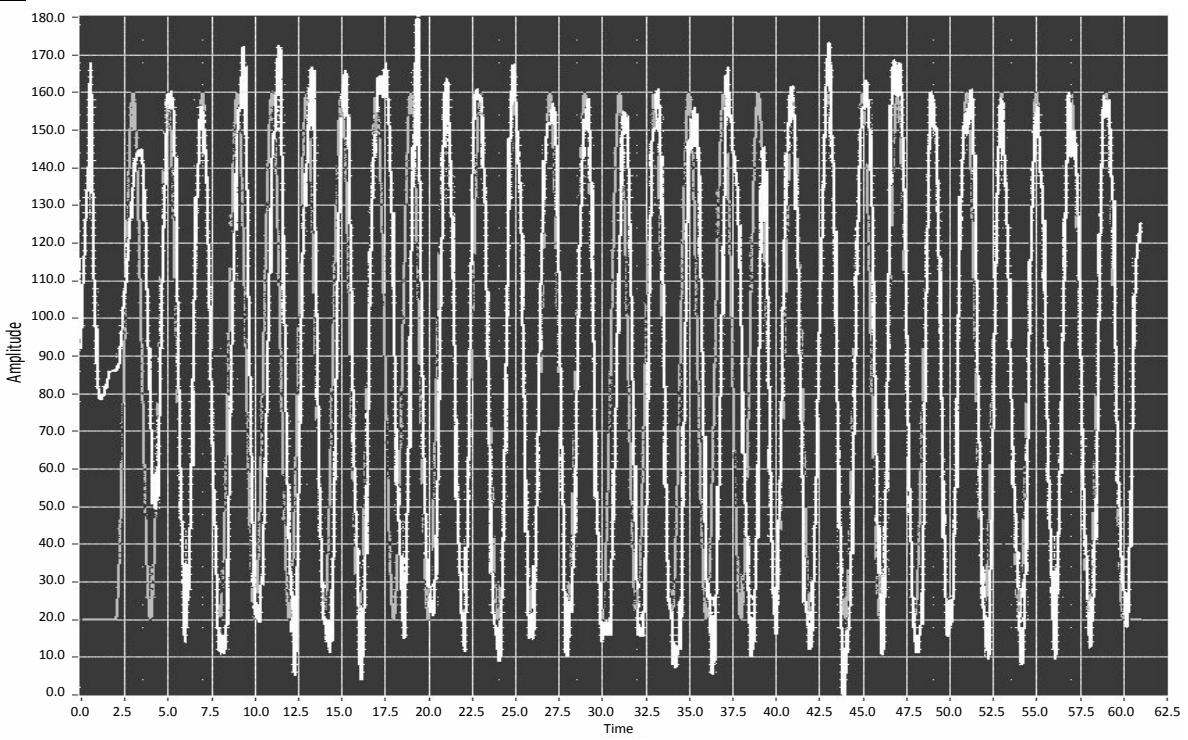

Figure 2: a) Screen shot of the display of the visuomotor tracking paradigm: Left column is the target, right column reflects the subject's movement. The bright portions indicate the ranges of motion, the dark grey portions indicate the actual state of movement. b) Display of the sinusoidal target movement (grey) and of the actual movement performance (white) during a recording of $0.5 \mathrm{~Hz}$ for 60 seconds. Ordinate (angle), abscissa (time). Note, the virtual overlay of both curves except for the turning points.

patients had a significant improvement in the trained affected hand ( $\mathrm{p}=0.0266$; Figure 4). Note that the healthy subjects (group A) had a better performance of their right hand before and after training in comparison to the trained affected hand of both patient groups over the three consecutive days ( $\mathrm{p}=0.009$, Figure 4 ). Note, that the patients performed far more heterogeneously initially as evident from the large standard deviations when compared with the healthy subjects. But the patients' performance became more similar particularly in the two measurements on the third day of training as evident from decreased standard deviations (Figure 4)

\section{Discussion}

Our study reports the first application of the multifunctional $\mathrm{PABLO}^{\mathrm{R}}$-device for monitoring movement performance in healthy volunteers and in neurological patients. Since this device can easily be applied, it is expected to be useful in the clinical environment and in neurorehabilitation. In this study we made two novel observations. Although we addressed some important neurophysiological issues of human motor control in an exploratory manner, we feel that interesting perspectives may be derived from our preliminary results.
First, longitudinal measurements on three consecutive days revealed that hand rotation improved in healthy subjects and neurological patients both after acute hemiparetic stroke and with mid-stage Parkinson's disease, respectively. Second, in healthy subjects training of hand rotation resulted in improved visuomotor coordination also of the contra-lateral, untrained hand. But this was not the case in the patients.

Concerning the healthy subjects we found that, apart from an actual gain in the performance quality, the visually guided modulation of hand rotation generalized from the trained dominant to the nontrained non-dominant hand. This corresponds to the earlier observation that after four weeks of training of a pegboard task there was a practice effect both for the trained and non-trained hand [21]. While our data showed a similar effect for the right and left hand, different types of manual performance and kinematic properties have ben found to be related to different types of hemispheric specialization [22,23]. Furthermore, handedness was shown to affect the transfer of sequence learning between the hands and of a drawing task [24,25]. Similarly, in learning of a signal reaction sequence task, transfer to the same stimulus sequence was possible without costs when the right hand was 
Citation: Seitz RJ, Kammerzell A, Samartzi M, Jander S, Wojtecki L, et al. (2014) Monitoring of Visuomotor Coordination in Healthy Subjects

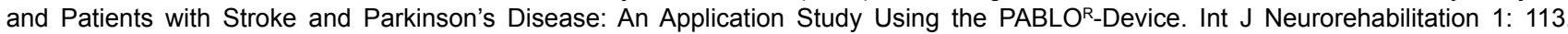
doi:10.4172/2376-0281.1000113

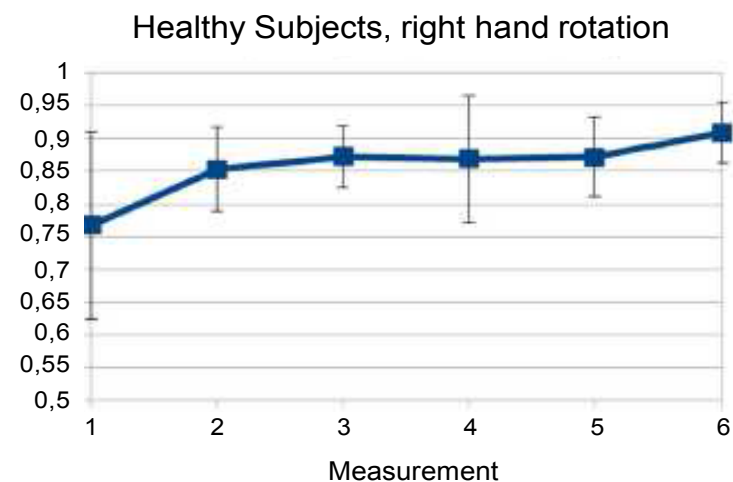

Healthy Subjects, left hand rotation

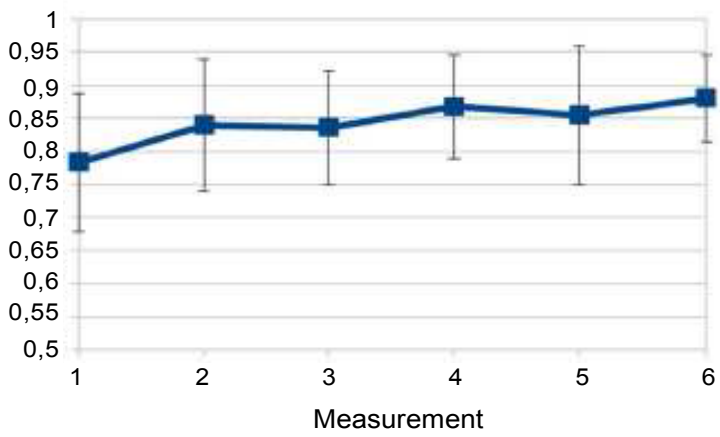

Stroke Patients, affected hand rotation

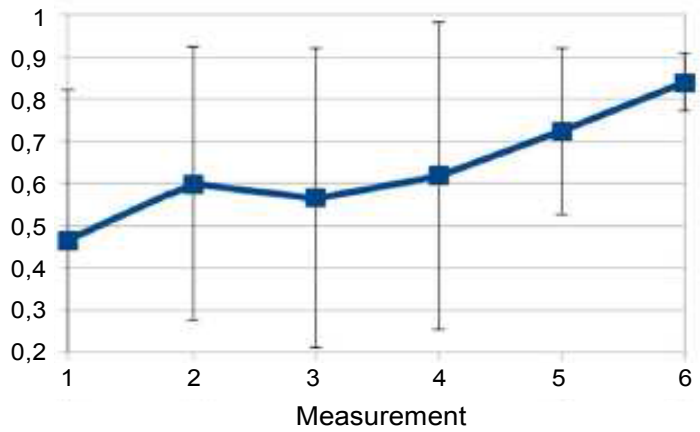

Stroke Patients, contralateral hand rotation

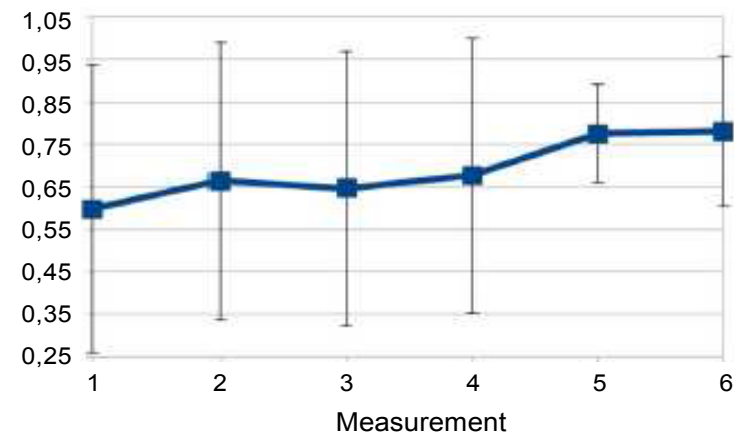

Figure 3: Visually guided modulation of hand rotation at the six different measurement points expressed as correlations of the actual performance with the target motion: 1 naïve, 2 after first training session, before training (3) and after training (4) on the second day, before training (5) and after training (6) on the third day. Improvement of the trained affected hand of the stroke patients $(p=0.026)$ is similar to the trained right hand in the healthy subjects $(p=0.0015)$. Ordinates: correlation coefficient, error bars $=\mathrm{SD}$.

$p=0.009$

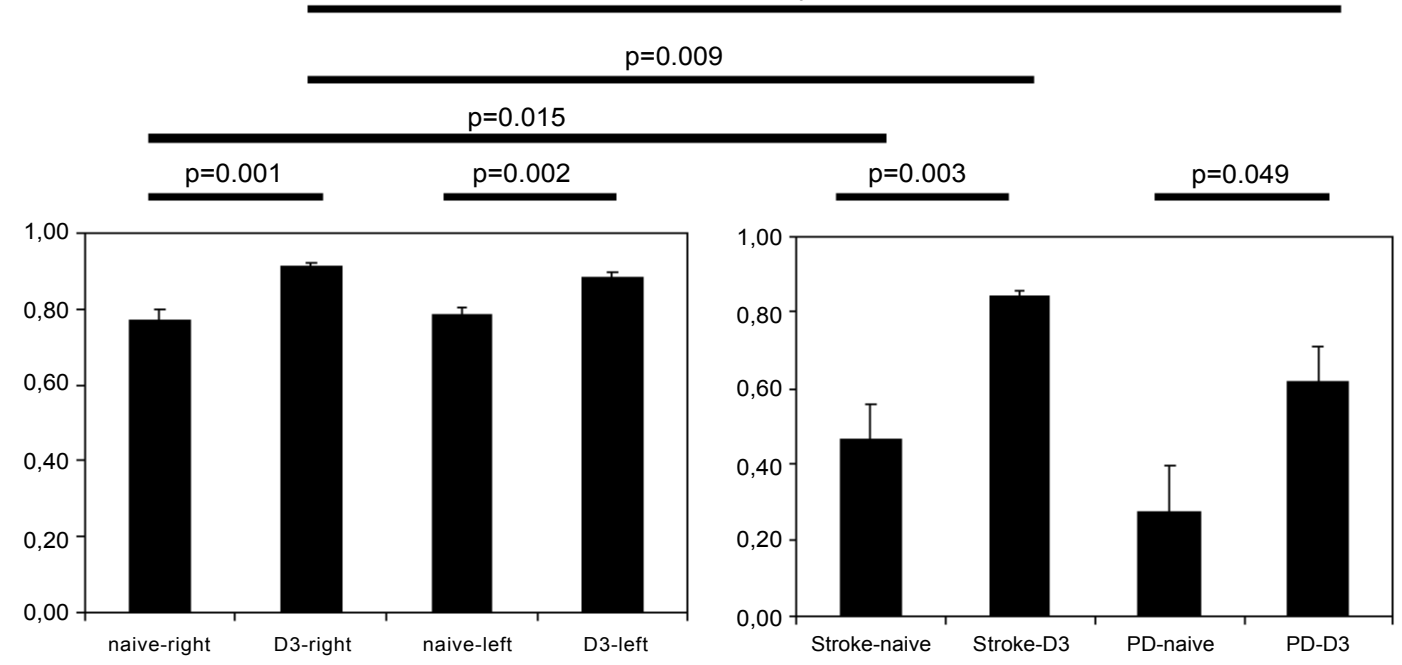

Figure 4: Visually guided modulation of hand rotation from the first measurement before training to the sixth measurement after training as depicted by the correlation of the actual performance data with the target motion. Improvement in the trained hand in the healthy subjects (left). Stroke and Parkinson's patients improved as well (right) but remained impaired as compared to the healthy controls. naive $=$ first measurement of day 1, D3 $=$ final measurement on day 3 . Ordinates: correlation coefficient, error bars $=S D$. 
trained, while transfer to the homologous finger sequence of the right hand was successful when the left hand was trained [26]. Critical for the interhemispheric transfer is the supplementary motor area (SMA) and may be involved in suppressing unwanted mirror movements as evidenced by transcranial magnetic stimulation [27,28]. Also, a stroke lesion may disconnect the two hemispheres which may preclude spread of a new skill to the opposite hemisphere and, thus, ipsilesional hand [29]. Conversely, recruitment of the non-affected hemisphere during recovery in the chronic phase after stroke has been advocated to facilitate generalization of a re-learned or new motor skill to the nonaffected hand by altered interhemispheric competition [30,31].

Training of force modulation resulted in a significant improvement in the healthy subjects, while there was no improvement of force modulation in the two patient groups. This was likely due to the fact that force control is a function of the corticospinal tract whose damage in stroke is a limiting factor for recovery $[32,33]$. Notably, the stroke patients were only slightly or moderately affected and were studied a few days after the insult. Most prominently, in the pinch grip task the isometric force production often resulted in pressing the index finger against the tip of the thumb rather than in performance of a gentle pinch grip of the tips of the first and second finger. This led to fatigue and a lacking improvement even in the healthy subjects. In contrast, modulation of isotonic hand rotation was a task both the healthy subjects and the patients could well comply with and the performance of which improved following training. Isotonic and isometric movements go along with similar patterns of electromyographic activity [34] and show the same effect on cortical excitability in healthy subjects and stroke patients [35]. Thus, they are likely to benefit in a similar way from dedicated training. While hand rotation movements are a fine motor skill that are subserved by a widespread cortical and subcortical circuit [13], its diadochokinetic character is expected to involve the cerebellum in accordance with clinical practice [14].

Recently, it was found that in Parkinson's disease the attentional resources are reduced which are mandatory for the control of visuomotor tracking [36]. Notably, target tracking is impaired in a bilateral fashion in Parkinson's disease even if the clinical presentation suggests a unilateral impairment [37]. In correspondence to the hypokinetic deficit in patients with Parkinson's disease, our patients showed a profound impairment in the hand rotation task before training. Training, however, resulted in a dramatic improvement such that the patients reached normal levels of task performance. This suggested that dedicated rehabilitative training in addition to pharmacotherapy is effective in Parkinson's disease to reverse the disease-related motor impairment.

Our data accord with a recent study that showed that in visuomotor power grip force tracking chronic stroke patients had an increased error, force variability and release duration [38]. Notably, patients and controls improved their tracking performance across repeated training blocks. Thus, continuous, explicit visuospatial finger-tracking was not sensitive to the post-training level of activity. Rather, sleepdependent consolidation likely occurred for tasks that were discrete in nature and did not rely on perceptual processing or reaction time [39]. It was found that visually guided corrective processes play a role especially for the generation of slow movements [40]. In fact, in a visuomotor tracking task the percentage of correct tracking increased upon cathodal stimulation of visual area V5 [41], but not when motor cortex, or visual cortex were stimulated. Improvement of visuomotor tracking was associated with a slow negative potential over the anterior frontal midline [42]. Improved feedforward control of visuomotor tracking correlated with activity in dorsal premotor cortex, inferior parietal lobule, supplementary motor area and cingulate motor area [43]. Modulation of feedback was associated with activity bilateral in posterior parietal lobule and right ventral premotor cortex. Trial by trial changes of kinematics correlated with activity in motor cortex and anterior cerebellum. Conversely, prefrontal lesions induced impairments in sequence learning both in pursuit tracking and serial reaction time tasks [44]. Moreover, patients with mild cerebellar dysfunction showed a significantly delayed performance when they were required to make coordinated eye and arm movements [45]. Accordingly, visuomotor tracking engages a widespread corticosubcortical network and, thus, influences the corticospinal motor output system.

From a technical point of view, training with the multifunctional $\mathrm{PABLO}^{\mathrm{R}}$-device offers the possibility to make the recorded data immediately available for inspection and off-line quantitative analysis for monitoring clinical interventions. Similarly to a dynamometer [46] grip force can be recorded with $\mathrm{PABLO}^{\mathrm{R}}$. But in contrast to the mechanical dynamometers, $\mathrm{PABLO}^{\mathrm{R}}$ is a multifunctional digital device offering many other options including the continuous, standardized measurements of visually controlled arm and hand movement data. Also, the PABLO ${ }^{\mathrm{R}}$ device is more versatile than accelerometers which are intended to record the amount of movement activity of a limb during wakefulness and sleep $[47,48]$. Moreover, $\mathrm{PABLO}^{\mathrm{R}}$ can be used for on-line performance control in virtual reality environments as for instance the Rehabilitation Gaming System [49]. Importantly, PABLO ${ }^{\mathrm{R}}$ provides a platform with different training scenarios in which subjects can learn to tune movements to greater precision by playing games in a virtual reality environment similarly to Wii devices [50]. Thus, training scenarios using $\mathrm{PABLO}^{\mathrm{R}}$ may impact also on activities of daily living particularly when used in training schedules of some weeks rather than just three consecutive days as in this study. Possibly, different recovery dynamics may become apparent in longer training periods as well.

This study has limitations. The subject groups cover different age ranges. Notably, the subjects behaved in a similar manner with similar performance rates among the younger controls and older stroke and Parkinsonian patients. Thus, there is no indication that efficacy of training tasks is substantially less in elderly as compared to young people. Specifically, the improvement of performance did not reveal a correlation with the age of the subjects. Moreover, since the test sessions were one minute short and not repeated, they are unlikely to induce a training effect as compared to the extensive visuomotor training sessions. In this study the range of action was adjusted to the actual performance level before the test session on each day. This resulted in an optimal recording of the performance data but may have obviated the possibility to use absolute performance measures. One may wonder if the improvement in the acute stroke patients was purely due to recovery. While this cannot be excluded entirely, the improvements in the healthy subjects and the patients with mid-stage Parkinson's disease who were in a stable "on"-situation during testing cannot be explained by recovery mechanisms. A randomized control trial with comparison to a different intervention will help to assess the magnitude of the training effect specific to the $\mathrm{PABLO}^{\mathrm{R}}$-device.

\section{Conclusion}

In this study we aimed at studying the improvement of visuomotor control of modulation of grip force, pinch grip and hand rotation with the multi-purpose $\mathrm{PABLO}^{\mathrm{R}}$-device. Data evaluation involved no complex modelling of the patient data but relied on the correlation of 
Citation: Seitz RJ, Kammerzell A, Samartzi M, Jander S, Wojtecki L, et al. (2014) Monitoring of Visuomotor Coordination in Healthy Subjects and Patients with Stroke and Parkinson's Disease: An Application Study Using the PABLOR-Device. Int J Neurorehabilitation 1: 113. doi:10.4172/2376-0281.1000113

the target and the actual behavioural data that was a robust parameter usable in the clinical environment. Operator given ranges of action allowed us to monitor improvements of force production and hand rotation movements in healthy subjects and patients with either acute stroke or Parkinson's disease. Our positive results reinforce a recommendation of the $\mathrm{PABLO}^{\mathrm{R}}$-device for larger clinical trials with longer training periods.

\section{Acknowledgement}

Supported by the consortium on the Rehabilitation Gaming System, AAL Joint Program 2008-1, European Commission, and Microsystems 2004-2009, Bundesministerium für Bildung und Forschung, VDI-VDE, Germany.

\section{References}

1. John J (1984) Grading of muscle power: comparison of MRC and analogue scales by physiotherapists. Medical Research Council. Int J Rehabil Res 7: 173-181.

2. Demeurisse G, Demol O, Robaye E (1980) Motor evaluation in vascular hemiplegia. Eur Neurol 19: 382-389.

3. Heller A, Wade DT, Wood VA, Sunderland A, Hewer RL, et al. (1987) Arm function after stroke: measurement and recovery over the first three months. J Neurol Neurosurg Psychiatry 50: 714-719.

4. Jebsen RH, Taylor N, Trieschmann RB, Trotter MJ, Howard LA (1969) An objective and standardized test of hand function. Arch Phys Med Rehabil 50: 311-319.

5. Fugl-Meyer AR, Jääskö L, Leyman I, Olsson S, Steglind S (1975) The poststroke hemiplegic patient. 1. a method for evaluation of physical performance. Scand J Rehabil Med 7: 13-31.

6. Goetz CG, Fahn S, Martinez-Martin P, Poewe W, Sampaio C (2007) Movement Disorder Society-sponsored revision of the Unified Parkinson's Disease Rating Scale (MDS-UPDRS): Process, format, and clinimetric testing plan. Mov Disord 22: 41-47.

7. Willingham DB (1998) A neuropsychological theory of motor skill learning Psychol Rev 105: 558-584.

8. Kilner JM, Baker SN, Salenius S, Hari R, Lemon RN (2000) Human cortical muscle coherence is directly related to specific motor parameters. J Neurosci 20: $8838-8845$

9. Seitz RJ, Matyas TA, Carey LM (2008) Neural Plasticity as a basis for motor learning and neurorehabilitation. Brain Impairment 9: 103-113.

10. Kwakkel G, Wagenaar RC, Twisk JW, Lankhorst GJ, Koetsier JC (1999) Intensity of leg and arm training after primary middle-cerebral-artery stroke: a randomised trial. Lancet 354: 191-196.

11. Gais S, Plihal W, Wagner U, Born J (2000) Early sleep triggers memory for early visual discrimination skills. Nat Neurosci 3: 1335-1339.

12. Gomez Beldarrain M, Grafman J, Ruiz de Velasco I, Pascual-Leone A, GarciaMonco C (2002) Prefrontal lesions impair the implicit and explicit learning of sequences on visuomotor tasks. Exp Brain Res 142: 529-538.

13. Ehrsson HH, Fagergren A, Jonsson T, Westling G, Johansson RS, et al. (2000) Cortical activity in precision- versus power-grip tasks: an fMRI study. $J$ Neurophysiol 83: 528-536.

14. Tracy JI, Faro SS, Mohammed FB, Pinus AB, Madi SM, et al. (2001) Cerebellar mediation of the complexity of bimanual compared to unimanual movements. Neurology 57: 1862-1869.

15. Seitz RJ, Donnan GA (2010) Role of neuroimaging in promoting long-term recovery from ischemic stroke. J Magn Reson Imaging 32: 756-772.

16. Colebatch JG, Gandevia SC (1989) The distribution of muscular weakness in upper motor neuron lesions affecting the arm. Brain $112: 749-763$.

17. Rothwell JC (2011) The motor functions of the basal ganglia. J Integr Neurosc 10: $303-315$

18. Oldfield RC (1971) The assessment and analysis of handedness: the Edinburgh inventory. Neuropsychologia 9: 97-113.

19. Brott T, Adams HP Jr, Olinger CP, Marler JR, Barsan WG, et al. (1989) Measurements of acute cerebral infarction: a clinical examination scale. Stroke 20: $864-870$.
20. Hoehn MM, Yahr MD (1967) Parkinsonism: onset, progression, and mortality. Neurology 17: 427-442

21. Schulze K, Lüders $E$, Jäncke $L$ (2002) Intermanual transfer in a simple motor task. Cortex 38: 805-815.

22. Boulinguez $P$, Nougier V, Velay $\mathrm{JL}$ (2001) Manual asymmetries in reaching movement control. I: Study of right-handers. Cortex 37: 101-122.

23. Boulinguez $P$, Nougier V, Velay JL (2001) Manual asymmetries in reaching movement control. I: study of left-handers. Cortex 37: 123-138.

24. Thut G, Cook ND, Regard M, Leenders KL, Halsband U, et al. (1996) Intermanual transfer of proximal and distal motor engrams in humans. Exp Brain Res 108: 321-327.

25. Chase C, Seidler R (2008) Degree of handedness affects intermanual transfer of skill learning. Exp Brain Res 190: 317-328.

26. Kirsch W, Hoffmann J (2010) Asymmetrical intermanual transfer of learning in a sensorimotor task. Exp Brain Res 202: 927-934.

27. Duque J, Mazzocchio R, Dambrosia J, Murase N, Olivier E, et al. (2005) Kinematically specific interhemispheric inhibition operating in the process of generation of a voluntary movement. Cereb Cortex 15: 588-593.

28. Perez MA, Tanaka S, Wise SP, Sadato N, Tanabe HC, et al. (2007) Neural substrates of intermanual transfer of a newly acquired motor skill. Curr Biol 17 1896-1902.

29. Lindenberg R, Zhu LL, Rüber T, Schlaug G (2012) Predicting functional motor potential in chronic stroke patients using diffusion tensor imaging. Hum Brain Mapp 33: 1040-1051

30. Murase N, Duque J, Mazzocchio R, Cohen LG (2004) Influence of interhemispheric interactions on motor function in chronic stroke. Ann Neurol 55: 400-409.

31. Tijs E, Matyas TA (2006) Bilateral training does not facilitate performance of copying tasks in poststroke hemiplegia. Neurorehabil Neural Repair 20: 473483.

32. Binkofski F, Seitz RJ, Arnold S, Classen J, Benecke R, et al. (1996) Thalamic metbolism and corticospinal tract integrity determine motor recovery in stroke. Ann Neurol 39: 460-470

33. Lindenberg R, Renga V, Zhu LL, Betzler F, Alsop D, et al. (2010) Structura integrity of corticospinal motor fibers predicts motor impairment in chronic stroke. Neurology 74: 280-287.

34. Freund HJ, Büdingen $\mathrm{HJ}$ (1978) The relationship between speed and amplitude of the fastest voluntary contractions of human arm muscles. Exp Brain Res 31: 1-12.

35. Woldag H, Renner C, Hummelsheim H (2008) Isotonic and isometric contractions exert the same amount of corticomotor system excitability in healthy subjects and patients after stroke. J Rehabil Med 40: 107-111.

36. Hocherman S, Moont R, Schwartz M (2004) Recruitment of attentional resources during visuomotor tracking: effects of Parkinson's disease and age. Brain Res Cogn Brain Res 21: 77-86.

37. Hocherman S, Giladi N (1998) Visuomotor control abnormalities in patients with unilateral parkinsonism. Neurology 50: 1648-1654.

38. Lindberg PG, Roche N, Robertson J, Roby-Brami A, Bussel B, et al. (2012) Affected and unaffected quantitative aspects of grip force control in hemiparetic patients after stroke. Brain Res 1452: 96-107.

39. Borich MR, Kimberley TJ (2011) Both sleep and wakefulness support consolidation of continuous, goal-directed, visuomotor skill. Exp Brain Res 214: 619-630.

40. Russell DM, Sternad D (2001) Sinusoidal visuomotor tracking: intermittent servo-control or coupled oscillations? J Mot Behav 33: 329-349.

41. Antal A, Nitsche MA, Kruse W, Kincses TZ, Hoffmann KP, et al. (2004) Direct current stimulation over $\mathrm{V} 5$ enhances visuomotor coordination by improving motion perception in humans. J Cogn Neurosci 16: 521-527.

42. Lang W, Lang M, Kornhuber A, Kornhuber HH (1986) Electrophysiological evidence for right frontal lobe dominance in spatial visuomotor learning. Arch Ital Biol 124: 1-13. 
Citation: Seitz RJ, Kammerzell A, Samartzi M, Jander S, Wojtecki L, et al. (2014) Monitoring of Visuomotor Coordination in Healthy Subjects and Patients with Stroke and Parkinson's Disease: An Application Study Using the PABLOR-Device. Int J Neurorehabilitation 1: 113. doi:10.4172/2376-0281.1000113

43. Grafton ST, Schmitt P, Van Horn J, Diedrichsen J (2008) Neural substrates of visuomotor learning based on improved feedback control and prediction. Neuroimage 39: 1383-1395

44. Beldarrain MG (2002) The cerebellum may be directly involved in cognitive functions. Neurology 59: 791.

45. Brown SH, Kessler KR, Hefter H, Cooke JD, Freund HJ (1993) Role of the cerebellum in visuomotor coordination. I. Delayed eye and arm initiation in patients with mild cerebellar ataxia. Exp Brain Res 94: 478-488.

46. Sunderland A, Tinson D, Bradley L, Hewer RL (1989) Arm function after stroke. An evaluation of grip strength as a measure of recovery and a prognostic indicator. J Neurol Neurosurg Psychiatry 52: 1267-1272.
47. Uswatte G, Miltner WH, Foo B, Varma M, Moram S (2000) Objective measurement of functional upper-extremity movement using accelerometer recordings transformed with a threshold filter. Stroke 31: 662-667.

48. Seitz RJ, Hildebold T, Simeria K (2011) Spontaneous arm movement activity assessed by accelerometry is a marker for early recovery after stroke. $\mathrm{J}$ Neuro 258: 457-463.

49. Cameirão MS, Badia SB, Oller ED, Verschure PF (2010) Neurorehabilitation using the virtual reality based Rehabilitation Gaming System: methodology, design, psychometrics, usability and validation. J Neuroeng Rehabil 7: 48

50. Saposnik G, Teasell R, Mamdani M, Hall J, Mcllroy W (2010) Stroke Outcome Research Canada (SORCan) Working Group. Effectiveness of virtual reality using Wii gaming technology in stroke rehabilitation: a pilot randomized clinica trial and proof of principle. Stroke 41: 1477-1484. 